\title{
STRATEGI PENGEMBANGAN BISNIS PRODUK OLAHAN \\ DAGING DI PT. SUMBER PANGAN JAYA CIKARANG - JAWA BARAT
}

\author{
Devi Oktaviani, Akhmad Riyadi Wastra* dan Eny Dwiningsih
}

\begin{abstract}
ABSTRAK
Identifikasi faktor internal dan eksternal dilakukan untuk mengetahui faktor-faktor yang mempengaruhi perkembangan bisnis PT. Sumber Pangan Jaya dengan menggunakan alat analisis IFE matrix (Internal Factor Evaluation Matrix) dan EFE matriks (External Factor Evaluation Matrix). Pengolahan data menggunakan IFE matrix menghasilkan faktorfaktor yang menjadi kekuatan utama dalam pengembangan bisnis PT. Sumber Pangan Jaya, berbagai produk yang ditawarkan dengan skor total 0,350, dan faktor yang menjadi kelemahan adalah konsumen tidak sepenuhnya berasal dari masyarakat kelas atas dengan total skor 0,093. Pengolahan data menggunakan EFE matriks menghasilkan faktor-faktor yang memiliki peluang besar dalam pengembangan bisnis PT. Sumber Pangan Jaya, yaitu kontinuitas bahan baku dari pemasok dengan skor total 0.300 , dan faktor yang merupakan ancaman utama adalah kenaikan harga bahan baku dengan total skor 0,106. Hasil pengolahan matriks IE menggambarkan posisi PT. Sumber Pangan Jaya berada di divisi IV, yang berarti strategi yang tepat adalah strategi yang bertujuan untuk pertumbuhan dan membangun. Hasil dari matriks SWOT diperoleh sembilan strategi alternatif yang dikembangkan oleh posisi perusahaan pada matriks IE, dalam hal ini strategi yang mungkin dilaksanakan adalah strategi intensif (penetrasi pasar, pengembangan pasar, dan pengembangan produk) dan strategi integrasi (integrasi ke depan, horisontal integrasi dan integrasi ke belakang). Berdasarkan hasil pengolahan data dengan QSPM, terdapat sembilan prioritas strategis yang dapat dijalankan oleh PT. Sumber Pangan Jaya.
\end{abstract}

Kata kunci: Strategi, SWOT, IFE, EFE, QSPM

\begin{abstract}
Identification of internal and external factors was conducted to determine the factors that influence the business development of PT. Sumber Pangan Jaya by using analytical tools IFE matrix (Internal Factor Evaluation Matrix) and EFE matrix (External Factor Evaluation Matrix). Processing data using IFE matrix produced the factors that become a major strength in the business development of PT. Sumber Pangan Jaya, the variety of products offered with a total score of 0.350, and the factor that becomes weakness is the consumers not entirely from upper class society with a total score of 0.093. EFE matrix processing produce factors that are major opportunities in business development PT. Sumber Pangan Jaya, namely the continuity of raw materials from supplier with a total score of 0.300, and a factor that is the main threat, the rise in raw material prices with a total score of 0.106. IE matrix processing results illustrate the position PT. Sumber Pangan Jaya are in the division IV, which means a strategy aimed at Growth and Build. The result of the SWOT matrix obtained 9 alternative strategies developed by the company's position on the matrix IE, in this case the strategy might be implemented is intensive strategy (market penetration, market development, and product development)
\end{abstract}


and integration strategy (forward integration, horizontal integration and backward integration). Based on the results of data processing with the matrix QSPM, there are nine strategic priorities that can be executed by PT. Sumber Pangan Jaya.

Keywords: Strategy, SWOT, IFE, EFE, QSPM

\section{PENDAHULUAN}

Subsektor peternakan merupakan salah satu sektor yang memberikan kontribusi yang signifikan di dalam pembangunan pertanian Indonesia. Subsektor peternakan memiliki peranan penting dalam menopang perekonomian regional karena subsektor ini selain memiliki peluang pasar yang sangat baik juga berperan penting bagi kelangsungan pembangunan secara keseluruhan, baik untuk meningkatkan gizi masyarakat maupun untuk memperluas lapangan kerja di sektor pertanian. Berdasarkan Litbang Kementerian Pertanian 2014, adanya peningkatan produksi daging di Indoesia khususnya daging sapi. PT. Sumber Pangan Jaya merupakan salah satu badan usaha swasta (perusahaan) yang bergerak di bidang hasil peternakan yaitu pengolahan daging. Mengingat adanya persaingan dalam lingkungan bisnis olahan daging, perusahaan dituntut untuk dapat menjalankan usahanya dengan efektif dan efesien, diharapkan PT. Sumber Pangan Jaya untuk mampu mengatur strategi dalam pengembangan bisnisnya dari internal maupun eksternal perusahaan.

\section{METODE PENELITIAN}

\section{Lokasi dan Waktu Penelitian}

Lokasi penelitian ini dilakukan di perusahaan yang bergerak di bidang pangan olahan daging. Perusahaan ini berlokasi di Jl. Jababeka IX Blok P 10B Cikarang-Jawa Barat dan kantor pusat berlokasi di Jl. Cilandak Tengah No.35, Jakarta Selatan. Waktu penelitian dimulai dari bulan November 2014 sampai Februari 2015.

\section{Metode Pengumpulan Data}

Pengumpulan data menggunakan metode wawancara, kuesioner, observasi, dan purposive sampling yang digunakan untuk memperoleh tanggapan.

\section{Metode Analisis Data}

Menganalisis data menggunakan metode analisis tiga tahap formulasi strategi, tiga tahap formulasi strategi yang terdiri dari pertama tahap masukan (input), kedua tahap pencocokan dan ketiga tahap keputusan. Analisis tiga tahap formulasi strategi yang digunakan dalam penelitian ini meliputi analisis Matriks Internal Factor Evaluation (IFE), Matriks Eksternal Factor Evaluation (EFE), analisis Matriks Internal-External (IE), analisis Matriks Strength-Weakness-Opportunities-

Threats (SWOT), dan analisis Quantitative Strategic Planning Matrix (QSP). 


\section{HASIL DAN PEMBAHASAN}

\section{Matriks Internal Factor Evaluation (IFE)}

Tabel 1. Matriks IFE

\begin{tabular}{|c|c|c|c|}
\hline Faktor-Faktor Strategis Internal & $\underset{\text { rata-rata }}{\text { Rating }}$ & $\begin{array}{c}\text { Bobot } \\
\text { rata-rata }\end{array}$ & Słor \\
\hline \multicolumn{4}{|l|}{ Kekuatan } \\
\hline Variasi p roduk yang ditawarkan & 4 & 0,0875 & $\mathbf{0 , 3 5 0}$ \\
\hline Jaringan distrbuusi produk & 4 & 0,0850 & 0,340 \\
\hline Me miliki layanandelivery order & 4 & 0,0825 & 0,330 \\
\hline Kapasitas produksi & 3,75 & 0,0775 & 0,290 \\
\hline Promosi yang dilakukan & 3,5 & 0,0850 & 0,297 \\
\hline $\begin{array}{l}\text { Fasilitasisarana prasarana produksi' } \\
\text { Operasi }\end{array}$ & 3,75 & 0,0775 & 0,290 \\
\hline $\begin{array}{l}\text { Sistem pe rmodalan usaha dan } \\
\text { pembukuan keuangan }\end{array}$ & 4 & 0,0700 & 0,280 \\
\hline Teraga kerja produksi yang terarmpil & 4 & 0,0800 & 0,320 \\
\hline $\begin{array}{l}\text { Hubungan antara atasan dengan } \\
\text { bawahan }\end{array}$ & 3,5 & 0,0875 & 0,306 \\
\hline \multicolumn{4}{|l|}{ Kelemahan } \\
\hline $\begin{array}{l}\text { Konsumen behum semua kalangan } \\
\text { (hanya konsumen leks menengah le } \\
\text { atas) }\end{array}$ & 1,25 & 0,0750 & 0,093 \\
\hline $\begin{array}{l}\text { Status ke perrilikan lokasi produksi dan } \\
\text { luas lo kasi produksi }\end{array}$ & 1 & 0,0950 & 0,095 \\
\hline $\begin{array}{l}\text { Ke tersediaan tenaga kerja } \\
\text { profesinal'kompeten }\end{array}$ & 1,75 & 0,0975 & 0,170 \\
\hline TOTAL & & 1 & 3,164 \\
\hline
\end{tabular}

Sumber: Data primer,2015

Berdasarkan hasil perhitungan matriks IFE yang dilakukan pada PT. Sumber Pangan Jaya yang menjadi kekuatan utamanya adalah variasi produk yang ditawarkan dengan nilai total 0,350. Sedangkan yang menjadi kekuatan kecil adalah sistem permodalan dan pembukuan keuangan dengan total nilai $0,28, \quad$ ini dikarenakan belum tersedianya ruangan ruang produksi, ruang penyimpanan bahan baku olahan daging, mesin-mesin dan peralatan untuk proses produksi olahan ikan, sehingga proses produksi untuk produk olahan dari bahan baku dasar ikan masih menggunakan sistem maklun yaitu proses produksi dilakukan di pabrik milik perusahaan lain.

Berdasarkan data pada matriks
Internal factor Evaluation (IFE), diketahui bahwa yang menjadi kelemahan utama bagi PT. Sumber Pangan Jaya adalah adalah konsumen belum mencakup semua kalangan (hanya kalangan menengah kelas menengah ke atas) dengan total nilai 0,093. Hal ini karena harga pokok penjualan (HPP) yang dikeluarkan oleh PT. Sumber Pangan Jaya tidak bisa untuk memasuki segmentasi pasar kelas menengah ke bawah karena biaya operasional produksi yang terbilang cukup tinggi. Divisi penelitian dan pengembangan (Research and Development) PT. Sumber Pangan Jaya belum menemukan komposisi formulasi yang tepat dan sedang melakukan riset untuk menciptakan produk dengan komposisi formulasi produk yang 
berbeda dengan biaya operasional produksi yang dikeluarkan tidak terlalu tinggi sehingga bisa memasuki segmen kelas menengah ke bawah. Sedangkan yang menjadi kelemahan kecil adalah ketersediaan tenaga kerja profesional dengan total nilai 0,170 . Secara keseluruhan, dapat diketahui bahwa total skor faktor-faktor strategis internal PT. Sumber Pangan Jaya adalah 3,164. Hal ini menunjukkan bahwa PT. Sumber Pangan Jaya berada pada kondisi diatas rata-rata $(3,0)$ dikatakan kuat.

\section{Matriks Eksternal Factor Evaluation (EFE)}

Tabel 2. Hasil Analisis Matriks Ekxemal Factor Evaluation (EFE)

\begin{tabular}{|c|c|c|c|}
\hline $\begin{array}{l}\text { Faktor-Faktor Strategis ElsternaI } \\
\text { Pehuang }\end{array}$ & $\begin{array}{l}\text { Rating } \\
\text { rata-rata }\end{array}$ & $\begin{array}{c}\text { Bobot } \\
\text { rata-rata }\end{array}$ & Skror \\
\hline Pola konsurnsi masyarakat pada fasfood & 3 & 0,0875 & 0.262 \\
\hline $\begin{array}{l}\text { Kontinuitas bahan b akudari } \\
\text { pemasokisuppliet }\end{array}$ & 3 & 0,1000 & $\mathbf{0 , 3 0 0}$ \\
\hline $\begin{array}{l}\text { Perkembargan te kro logi info masi } \\
\text { kormunikasi, te kno bgi pengolahan } \\
\text { pangan dan distrbusi }\end{array}$ & 2,5 & 0,0925 & 0,231 \\
\hline Hambatan yang kuat bag i produse n baru & 2 & 0,0950 & 0,190 \\
\hline $\begin{array}{l}\text { Pasar yang masih terbukalpangsa pasar } \\
\text { masih luas } \\
\text { Ancaman }\end{array}$ & 2,75 & 0,0700 & 0,192 \\
\hline Ke naikan BBM dan TDL & 1,75 & 0,0725 & 0,126 \\
\hline Kenaiknn harga bahan b aku & 1,25 & 0,0850 & 0,106 \\
\hline Belum adanya sertifikat HACCP dan ISO & 2,75 & 0,0750 & 0,206 \\
\hline Pembatasan kuota impor daging & 2 & 0,0800 & 0,160 \\
\hline Pesaing se je nis & 2,5 & 0,0775 & 0,193 \\
\hline Produk subtitusi & 3,5 & 0,0850 & 0,297 \\
\hline Daya beli masyarakat fluktuatif & 2,25 & 0,0800 & 0,180 \\
\hline TOTAL & & 1 & 2,446 \\
\hline
\end{tabular}

Berdasarkan perhitungan matriks EFE peluang yang sangat berpengaruh terhadap pengembangan bisnis PT. Sumber Pangan Jaya adalah kontinuitasbahan baku dari pemasok/supplier dengan total nilai 0,300. Sedangkan peluang yang sangat kecil pengaruhnya adalah hambatan yang kuat bagi produsen baru dengan total nilai 0,190 . Hambatan yang cukup kuat bagi produsen baru untuk mendirikan usaha olahan daging dengan dilengkapi surat perizinan usaha, dan membutuhkan sarana/prasarana produksi olahan daging dengan biaya yang tidak sedikit menandakan bahwa jumlah perusahaan olahan daging tidak berpotensi dengan cepat mengalami peningkatan jumlah perusahaan, hal ini berarti tidak banyak pesaing-pesaing baru sejenis yang bermunculan sehingga perusahaan memiliki kesempatan untuk dapat mempertahankan dan memperluas pangsa pasar.

Berdasarkan data pada matriks Eksternal Factor Evaluation (EFE), diketahui bahwa ancaman yang berpengaruh pada PT. Sumber Pangan Jaya adalah kenaikan harga bahan baku dengan total nilai 0,106 . Sedangkan ancaman kecil bagi PT. Sumber Pangan Jaya adalah adanya produk subtitusi dengan total nilai 0,297. Secara keseluruhan, dapat diketahui bahwa total skor faktor-faktor strategis eksternal PT. Sumber Pangan adalah 2,446 . 
Matriks Internal-Eksternal (IE)

Tabel3. Matriks IE

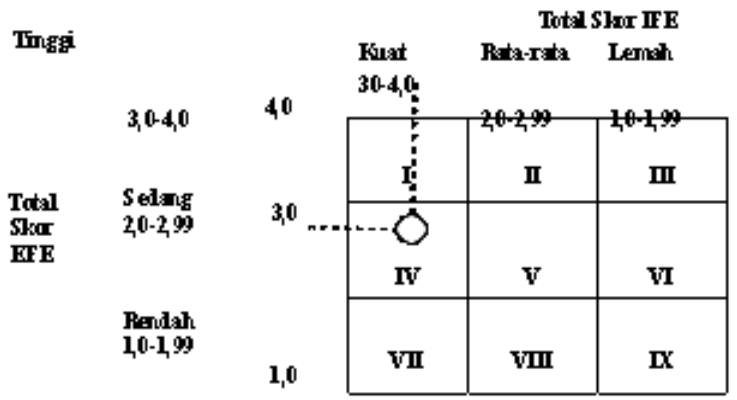

Sumber: Data primer, 2015.

Matriks IE digunakan untuk mengetahui posisi PT. Sumber Pangan Jaya saat ini dengan berdasarkan dari total skor bobot matriks IFE dan matriks EFE. Besarnya total skor bobot IFE sebesar 3,164 sedangkan total bobot skor EFE sebesar 2,446. Berdasarkan total skor bobot yang diperoleh dari matriks IFE dan matriks EFE, menempatkan PT. Sumber Pangan Jaya berada pada kuadran IV, artinya strategi yang dapat dilaksanakan pada sel IV adalah tumbuh dan kembangkan/bina (Growth and Build). 
Perumusan Alternatif Strategi PT. Sumber Pangan Jaya

Matriks Strenghts Weakness Oppourtunities Threats (SWOT)

Tabel 4.Mariks SWOT

\begin{tabular}{|c|c|c|}
\hline . & 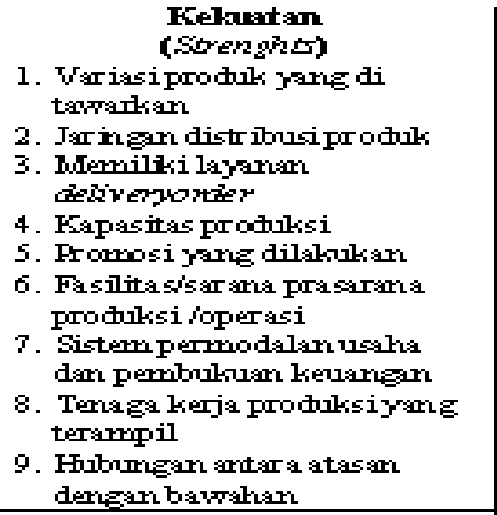 & 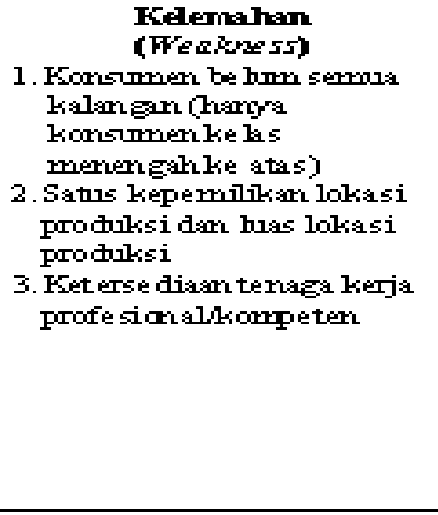 \\
\hline Pehuantr (Oportanities) & Strategi S-O & Strategi W-0 \\
\hline 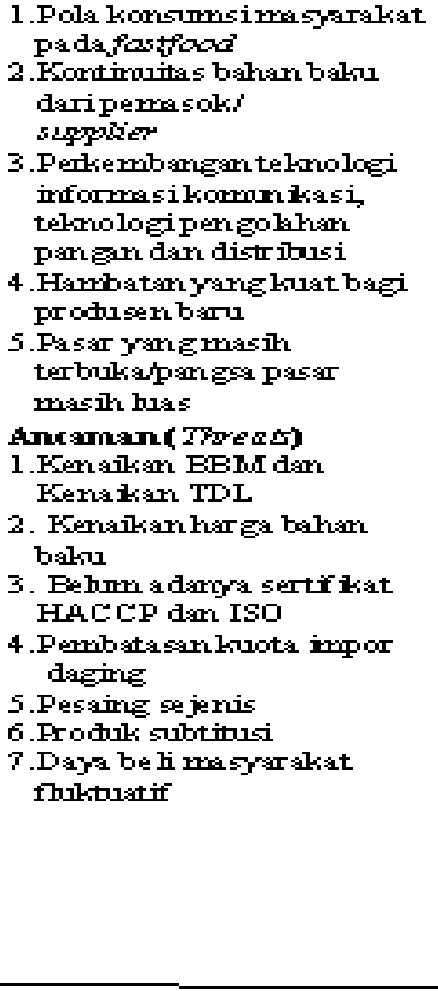 & 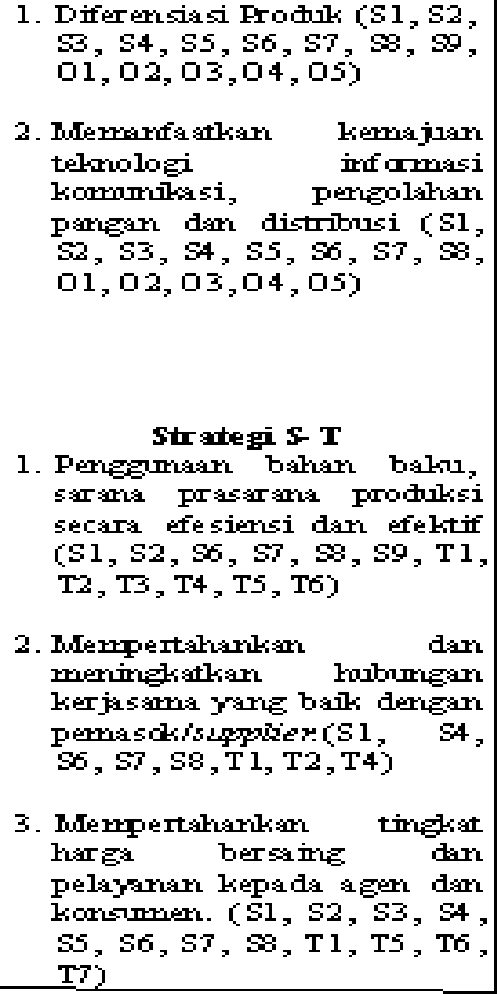 & 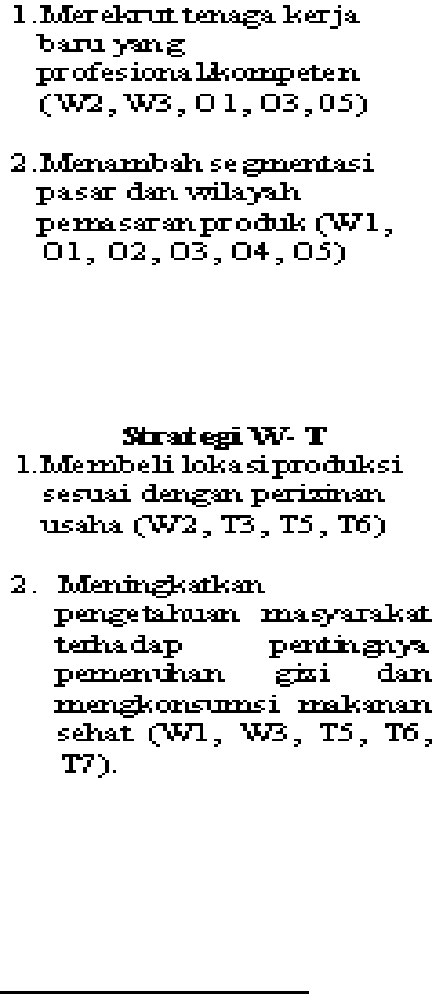 \\
\hline
\end{tabular}

Sumber: Data primer diolah, 2015.

Alternatif

Pengembangan Bisnis PT.

Sumber Pangan Jaya Strategi S-O

1. Diferensiasi Produk (S1, S2, S3, S4, S5, S6, S7, S8, S9, O1, O2, O3, 04, O5).

2. Memanfaatkan Kemajuan Teknologi

Komunikasi, Informasi Pengolahan

Pangan dan Distribusi (S1, S2,
S3, S4, S5, S6, S7, S8, O1, O2, O3, O4, O5).

\section{Strategi W-O}

1. Merekrut Tenaga Kerja Baru yang Profesional/Kompeten (W2,W3,O1, O3, O5).

2. 2. Menambah Segmentasi Pasar dan Wilayah Pemasaran Produk (W1, O1, 
$\mathrm{O} 2, \mathrm{O} 3, \mathrm{O} 4, \mathrm{O} 5)$

\section{Strategi S-T}

1. Penggunaan Bahan Baku, Sarana Prasarana Produksi secara Efesiensi dan Efektif. (S1, S2, S6, S7, S8, T1, T2, T3, T4, T5, T6).

2. Mempertahankan dan Meningkatkan Hubungan Kerjasama yang Baik dengan

3. Pemasok/Supplier (S1, S4, S6, $\mathrm{S} 7, \mathrm{~S} 8, \mathrm{~T} 1, \mathrm{~T} 2, \mathrm{~T} 4)$.

4. Mempertahankan Tingkat Harga Bersaing dan Pelayanan kepada Agen dan

Konsumen (S1, S2, S3, S4, S5, S6, S7, S8, T1, T5, T6, T7).

\section{Strategi W-T}

1. Membeli Lahan untuk Lokasi Produksi sesuai dengan Perizinan Usaha (W2, T3, T5, T6).

2. Meningkatkan

Pengetahuan Masyarakat terhadap Pentingnya

Pemenuhan Gizi dan Mengkonsumsi Makanan Sehat (W1, W3, T5, T6, T7).

\section{Penentuan Prioritas Strategi PT.}

\section{Sumber Pangan Jaya}

Alternatif strategi yang diperoleh dari matrik SWOT antara lain:

1. Diferensiasi produk.

2. Memanfaatkan kemajuan teknologi informasi komunikasi, pengolahan pangan dan distribusi.

3. Merekrut tenaga kerja baru yang profesional/kompeten.

4. Menambah segmentasi pasar dan wilayah pemasaran produk.

5. Penggunaan bahan baku, sarana prasarana produksi secara efesien dan efektif.

6. Mempertahankan dan meningkatkan hubungan kerjasama yang baik dengan pemasok/supplier.

7. Mempertahankan tingkat harga bersaing dan pelayanan kepada konsumen.

8. Membeli lahan untuk lokasi produksi sesuai dengan perizinan usaha.

9. Meningkatkan pengetahuan masyarakat terhadap pentingnya pemenuhan gizi dan makanan sehat.

Berdasarkan perhitungan dari QSPM melalui evaluasi strategi dari matriks SWOT maka diperoleh penentuan prioritas strategi seperti pada Tabel 5.

Tabel 5. Prioritas Strategi Pengembangan Bisnis PT. Sumber Pangan Jaya

\begin{tabular}{|c|c|c|}
\hline NO. & PRIORITAS STRATEGI & $\begin{array}{l}\text { TOTAL } \\
\text { SKOR }\end{array}$ \\
\hline 1. & $\begin{array}{l}\text { Memanfaatkan kemajuan teknologi informasi komunikasi, pengolahan } \\
\text { pangan dan distribusi }\end{array}$ & 6,398 \\
\hline 2. & Diferensiasi produk & 6,270 \\
\hline 3. & $\begin{array}{l}\text { Mempertahankan tingkat harga bersaing dan pelayanan kepada agen } \\
\text { dan konsumen }\end{array}$ & 5,751 \\
\hline 4. & Menambah segmentasi pasar dan wilayah pemasaran produk & 5,743 \\
\hline 5. & $\begin{array}{l}\text { Meningkatkan pengetahuan masyarakat terhadap pentingnya } \\
\text { pemenuhan gizi dan makanan sehat }\end{array}$ & 5,450 \\
\hline 6. & $\begin{array}{l}\text { Penggunaan bahan baku dan sarana prasarana produksi secara } \\
\text { efesiensi dan efektif }\end{array}$ & 5,286 \\
\hline
\end{tabular}




\begin{tabular}{|c|l|c|}
\hline 7 & Membeli lahan untuk lokasi produksi sesuai dengan perizinan usaha & 4,881 \\
\hline 8 & $\begin{array}{l}\text { Mempertahankan dan meningkatkan hubungan kerjasama yang baik } \\
\text { dengan pemasok/supplier }\end{array}$ & 4,803 \\
\hline 9. & Merekrut tenaga kerja baru yang profesional/kompeten. & 4,748 \\
\hline
\end{tabular}

Sumber : Data Primer (Diolah), 2015

\section{KESIMPULAN}

1. Identifikasi faktor internal pada PT. Sumber Pangan Jaya yang menjadi kekuatan utama adalah variasi produk yang ditawarkan dengan skor 0,350. Sementara itu, faktor-faktor lain yang teridentifikasi menjadi kekuatan dari PT. Sumber Pangan Jaya antara lain : jaringan distribusi produk, memiliki layanan delivery order, tenaga kerja produksi yang terampil, hubungan antara atasan dengan bawahan, promosi yang dilakukan, kapasitas produksi, fasilitas/sarana prasarana produksi/operasi, sistem permodalan usaha dan pembukuan keuangan. Sedangkan faktor internal yang menjadi kelemahan utama adalah konsumen belum semua kalangan (hanya konsumen kelas menengah ke atas) dengan skor 0,093. Sementara itu, faktor-faktor lain yang menjadi kelemahan dari PT. Sumber Pangan Jaya antara lain : status kepemilikan lokasi produksi dan luas lokasi produksi, dan ketersediaan tenaga kerja profesional/kompeten.

2. Identifikasi faktor eksternal pada PT. Sumber Pangan Jaya yang menjadi peluang utama adalah kontinuitas bahan baku dari pemasok/supplier dengan skor 0,300. Sementara itu, faktorfaktor eksternal lain yang teridentifikasi menjadi peluang bagi PT. Sumber Pangan Jaya antara lain : pola konsumsi masyarakat pada fastfood, perkembangan teknologi di bidang informasi komunikasi, teknologi pengolahan pangan dan distribusi, pasar yang masih terbuka/pangsa pasar masih luas, dan hambatan yang kuat bagi produsen baru. Sedangkan faktor eksternal yang menjadi ancaman utama bagi PT. Sumber Pangan Jaya adalah kenaikan harga bahan baku dengan skor 0,106. Sementara itu, faktor-faktor lain yang teridentifikasi menjadi ancaman bagi PT. Sumber Pangan Jaya antara lain: kenaikan bahan bakar minyak (BBM) dan Tarif Dasar Listrik (TDL), pembatasan kuota impor daging, daya beli masyarakat fluktuatif, pesaing sejenis, belum adanya sertifikat HACCP dan ISO,dan produk subtitusi.

3. Berdasarkan total skor bobot yang diperoleh dari matriks IFE dan matriks EFE sebesar 3,164 dan 2,466, menempatkan PT. Sumber Pangan Jaya berada pada kuadranIV, artinya strategi yang dapat dilaksanakan pada sel IV adalah tumbuh dan kembangkan/bina (Growth and Build). Strategi yang umum digunakan pada posisi ini adalah melakukan penetrasi pasar, pengembangan pasar, pengembangan produk, integrasi ke depan, integrasi ke belakang, dan integrasi horizontal.

4. Alternatif strategi dalam 
pengembangan PT. Sumber Pangan Jaya dengan menggunakan matriks SWOT. Strategi dengan menggunakan kekuatan yang memanfaatkan peluang yang ada (SO) yaitu diferensiasi produk dan memanfaatkan kemajuan teknologi di bidang informasi komunikasi, teknologi pengolahan pangan, dan distribusi. Strategi dengan memperkecil kelemahan dengan memanfaatkan peluang yang ada (WO) yaitu, merekrut tenaga kerja baru yang profesional/kompeten, menambah segmentasi pasar dan wilayah pemasaran produk. Strategi yang menggunakan kekuatan untuk meminimalisir ancaman yang ada (ST) yaitu penggunaan bahan baku, sarana prasarana produksi/operasi secara efesien dan efektif, mempertahankan dan meningkatkan hubungan kerjasama dengan pemasok/supplier, mempertahankan tingkat harga bersaing dan pelayanan kepada konsumen. Strategi dengan meminimalisir kelemahan umtuk mengantisipasi ancaman (WT) yaitu membeli lahan untuk lokasi produksi sesuai dengan perizinan usaha dan meningkatkan pengetahuan masyarakat terhadap pentingnya pemenuhan gizi dan makanan sehat.

5. Prioritas utama yang dihasilkan dari QSPM yang dapat dijalankan PT.

Sumber Pangan Jaya adalah memanfaatkan kemajuan teknologi informasi komunikasi, teknologi pengolahan pangan dan distribusi dengan total skor 6,398. Kemudian urutan prioritas selanjutnya adalah diferensiasi produk, mempertahankan tingkat harga bersaing dan pelayanan kepada konsumen, menambah segmentasi pasar dan wilayah pemasaran produk, meningkatkan pengetahuan masyarakat terhadap pentingnya pemenuhan gizi dan makanan sehat, penggunaan bahan baku dan sarana prasarana produksi secara efesiensi dan efektif, membeli lahan untuk lokasi produksi sesuai dengan perizinan usaha, mempertahankan dan meningkatkan hubungan kerjasama yang baik dengan pemasok/supplier, merekrut tenaga kerja baru yang profesional/kompeten.

\section{SARAN}

Berdasarkan penelitian yang dilakukan oleh penulis, maka dapat dikemukakan beberapa saran yang dapat diajukan kepada PT. Sumber Pangan Jaya antara lain:

1. Sebaiknya PT. Sumber Pangan Jaya fokus terhadap alternatif strategi memanfaatkan perkembangan teknologi di bidang informasi komunikasi, teknologi pengolahan pangan, dan teknologi distribusi sebagai prioritas strategi yang didapatkan PT. Sumber Pangan Jaya agar dapat terus mengembangkan bisnisnya, mampu menghadapi laju persaingan serta dapat menjadi pemimpin pasar (Market Leader).

2. Sebaiknya PT. Sumber Pangan Jaya melakukan pengukuran dan 
penilaian atau evaluasi terhadap strategi yang telah di implementasikan dalam jangka waktu setiap satu tahun sekali, atau maksimal 2 kali dalam satu tahun untuk melihat strategi yang sudah dilaksanakan sudah sesuai atau belum dengan perencanaan atau perlu adanya perubahan.

3. Perusahaan dapat menjadikan alternatif-alternatif strategi dari hasil penelitian ini sebagai bahan acuan atau pertimbangan untuk pengambilan keputusan bagi pengembangan bisnisnya.

\section{DAFTAR PUSTAKA}

[BPS] Badan Pusat Statistik. Persentase Sumbangan/Kontribusi

Subsektor Pertanian terhadap Domestik Bruto Atas Dasar Harga Berlaku. Jakarta : Badan Pusat Statistik. Diakses 18 Desember 2014 from http://www.bps.go.id

[BPS] Badan Pusat Statistik. Produk Domestik Bruto Non-Migas Atas Dasar Harga Berlaku Menurut Lapangan Usaha (Miliar Rupiah). Jakarta : Badan Pusat Statistik. Diakses 18 Desember 2014 from http://www.bps.go.id

[BPS] Badan Pusat Statistik. Produk Domestik Bruto Non-Migas Atas Dasar Harga Konstan Tahun 2000. Jakarta : Badan Pusat Statistik. Diakses 18 Desember 2014 from http://www/bps.go.id

[BPS] Badan Pusat Statistik. Jumlah Penduduk Indonesia. Jakarta : Badan Pusat Statistik. Diakses 18 Desember 2014 from http://www.bps.go.id

[BPS] Badan Pusat Statistik. Rata-Rata Pengeluaran Makanan Jadi di Daerah Perkotaan dan Pedesaan Menurut Golongan Pengeluaran Per Kapita Per bulan.Jakarta : Badan Pusat Statistik. Diakses 18 Desember 2014 from http://www.bps.go.id

Abrianto. 2011. Penanganan Daging Sapi Pasca Panen. Diakses 19 Februari 2015.

Sanusi, Anwar. Metodologi Penelitian Bisnis. Jakarta: Salemba Empat, 2013. Badan Penelitian dan Pengembangan Sosial Ekonomi dan Kebijakan Pertanian. Konsumsi Daging di Indonesia Tahun 2009-2014. Jakarta : Kementrian Pertanian. Diakses 19 Februari 2015 from http:///www.litbang.pertanian.g o.id

Badan Penelitian dan Pengembangan Sosial Ekonomi dan Kebijakan Pertanian. Produksi Daging di Indonesia Tahun 2009-2014. Jakarta : Kementrian Pertanian. Diakses 19 Februari 2014 from http://www.litbang.pertanian.go. id

David, Fred R. Strategic Management, Edisi Ke-10. Jakarta : PT. Prenhallindo, 2008.

David, Fred R. Strategic Management, Edisi Ke-12. Jakarta : Salemba Empat, 2011.

$\underset{\text { Keputusan }}{\text { Kementrian }} \begin{array}{r}\text { RI. } \\ \text { Menteri }\end{array}$ 
Kesehatan

No

1202/Menkes/SK/VII/2003

tentang Indikator Indonesia

Sehat 2010 dan Pedoman

Penetapan Indikator Provinsi

Sehat dan Kabupaten/Kota

Sehat, Jakarta : Kementrian

Kesehatan RI. Diakses 18

Desember 2014 from

http://www.depkes.go.id

Downey, W. David \& Erickson, Steven P. Manajemen Agribisnis. Jakarta : Erlangga, 1987. Asosiasi Pengolahan Daging Indonesia.

Perkembangan Industri

Pengolahan Daging di

Indonesia. Jakarta : FAO dalam

IPB Convention Center, 2011.

Fatchur Rochman, Fadlika. 2011. Strategi pengembangan Bisnis (Studi Kasus PT. Ojid Kharisma Nusantara. [Skripsi] Sarjana Sosial Ekonomi Pertanian, Fakultas Sains dan Teknologi, Universitas Islam Negeri Syarif Hidayatullah Jakarta.

Penyesuaian Tarif Dasar Listrik (TDL). Artikel diakses 20 Desember 2014 from http://esdm.go.id/berita/listrik/3 9-listrik/6864-penjelasanmenteri-esdmterkaitpenyesuaian-tarif-dasarlistrik.html.

Kementrian Perdagangan izinkan impor daging. Artikel diakses 20 Januari 2015 from http://www.agroindonesia.co.id/ 201501/20/kemendag-izinkanimpor-daging-12-246ton/

Harga Premium Mulai 1 Januari 2015. Artikel diakses 19 Februari
2015 from

http://www.intriknews.com/201

4/12/mulai-1-januari-2015-

harga-premium-rp.html.

Kebijakan Pembatasan Kuota Daging Impor, Importir Resah. Artikel diakses 20 Februari 2015 from http://www.kebijakanpembatasan-kuota-dagingimpor-tahun-2014-kuota-impordaging-akan-dibatasi-importirresah.

Tarif Dasar Listrik (TDL) Naik, Kementrian Perindustrian Siapkan Insentif Untuk Perusahaan Non-Tbk. Artikel diakses 20 Desember 2014 from

http://www.tempo.co/read/news /2014/06/06/092583076/TDL-

Naik- Kemenperin-Siapkan Insentif-untuk-Non-Tbk.

Jokowi Akan Turunkan BBM Menjadi Rp. 6.500 per Liter. Artikel diakses $\quad 29 \quad$ Februari 2015 from http://www.tempo.co/read/news/ 2015/01/15/090635014/JokowiAkan- Turunkan-BBM-Jadi-Rp6500-per-Liter.

Jogiyanto. Metodologi Penelitian Bisnis. Yogyakarta: BPFE-Yogyakarta, 2009.

Kementrian Kesehatan RI. 2014. Daftar Komposisi Zat Gizi Pangan Indonesia, Jakarta. Diakses 18 Desember 2014 from www.depkes.go.id

Kotler, Philip. Manajemen Pemasaran. Jakarta : PT. Prenhallindo, 2002. Nazir, Moh. Metode Penelitian. Ghalia Indonesia, Bogor, 2011. 
Porter , ME. Strategi Bersaing : Teknik Menganalisis Industri dan Pesaing, Jakarta : Erlangga, 1997.

Lawrie, RA. Ilmu Daging. Alih bahasa: Prof. Dr. Aminuddin Parakkasi. Jakarta: Universitas Indonesia, 2003.

Rangkuti, Freddy. Analisis SWOT Teknik Membedah Kasus Bisnis. Jakarta: PT. Gramedia, 2014

Soeparno. Ilmu dan Teknologi Daging. Yogyakarta: Gajah Mada Press, 2005. Soeparno. Ilmu Nutrisi dan Gizi Daging. Yogyakarta: Gadjah Mada University Press, 2011.

Sugiyono. Metodologi Penelitian Bisnis. Bandung: CV. Alfabeta, 1999.

Umar, Husein. Strategic Management in Action. Jakarta: Gramedia Pustaka

Utama, 2008.

Pearce dan Robinson. Manajemen Strategi, Jilid Satu. Jakarta : Binarupa Aksara. 1997.

* Alamat Korespondensi:

riyadi.wastra@uinjkt.ac.id 
Jurnal Agribisnis, Vol. 12, No. 1, Juni 2018, [27 - 31 ]

ISSN : 1979-0058 